\title{
Day Length and Weather Effects on Children's Physical Activity and Participation in Play, Sports, and Active Travel
}

\section{Anna Goodman, James Paskins, and Roger Mackett}

\begin{abstract}
Background: Children in primary school are more physically active in the spring/summer. Little is known about the relative contributions of day length and weather, however, or about the underlying behavioral mediators. Methods: 325 British children aged 8 to 11 wore accelerometers as an objective measure of physical activity, measured in terms of mean activity counts. Children simultaneously completed diaries in which we identified episodes of out-of-home play, structured sports, and active travel. Our main exposure measures were day length, temperature, rainfall, cloud cover, and wind speed. Results: Overall physical activity was higher on long days ( $\geq 14$ hours daylight), but there was no difference between short $(<9.5$ hours) and medium days (10.2-12.6 hours). The effect of long day length was largest between 5 PM and 8 PM, and persisted after adjusting for rainfall, cloud cover, and wind. Up to half this effect was explained by a greater duration and intensity of out-of-home play on long days; structured sports and active travel were less affected by day length. Conclusions: At least above a certain threshold, longer afternoon/evening daylight may have a causal role in increasing child physical activity. This strengthens the public health arguments for daylight saving measures such as those recently under consideration in Britain.
\end{abstract}

Keywords: youth, seasonal variation, public health, daylight

Promoting physical activity in childhood has become a policy priority, reflecting its potential to confer substantial benefits to physical and mental health. ${ }^{1-4}$ Understanding when and why children are active is an important step in designing effective public health interventions to achieve this goal. This includes understanding how children's physical activity varies across the day, week, and year-and ideally also the interrelationship between variation at these different levels.

Such temporal variation has generally received less research attention than the relationship between overall physical activity and relatively fixed characteristics of the child or their environment. ${ }^{5-7}$ Nevertheless, several large $(\mathrm{N}>100)$ population-based studies have examined the effects of season or day length in the US, ${ }^{8,9}$ Canada, ${ }^{10}$ the UK, ${ }^{11,12}$ Denmark, ${ }^{13}$ Norway, ${ }^{14}$ Sweden, ${ }^{15}$ Cyprus, ${ }^{16}$ and New Zealand. ${ }^{17}$ These studies collected objective measures of physical activity from a total of 11,476 children aged 4 to 13, approximately $90 \%$ of whom were aged 9 to 11 . All but one ${ }^{10}$ reported higher activity levels in the spring and/or summer than in the autumn and/or winter, with moderate to substantial effect sizes. Likewise a recent, broader review (including smaller studies

Goodman is with the Faculty of Epidemiology and Population Health, London School of Hygiene and Tropical Medicine, London, United Kingdom. Paskins and Mackett are with the Centre for Transport Studies, University College London, United Kingdom. and studies with nonobjective measurement of physical activity) reported seasonal differences in 29 out of 35 studies of 2- to 19 -year-olds. ${ }^{18}$ This included 6 out of 7 studies from the UK, ${ }^{11,12,19-22}$ the exception being one very small study $(\mathrm{N}=34){ }^{23}$

There is therefore consistent evidence of seasonal differences in the overall physical activity of children in primary school in Europe, North America, and New Zealand. Almost nothing, however, is known about the timing and causes of these differences. Only 2 studies examined when in the day or week seasonal effects were greatest, reporting larger effects during the weekend in Norway and during after school hours in Norway and Cyprus. ${ }^{14,16}$ No study investigated the behavioral mediators underlying the observed seasonal differences, although several discuss changes in the amount of outdoor play as a plausible candidate. This hypothesis is indirectly supported by one study of British 11-year-olds which reports a spring/ summer increase in both the duration and the activity intensity of time spent outdoors after school. ${ }^{24}$ Finally, very little is known about the relative contribution of day length and different aspects of the weather in generating seasonal differences, a research gap highlighted in recent studies and reviews. 9,11,14,18,25 To our knowledge, only 1 study of 5- to 12-year-olds in New Zealand has examined this issue, reporting that rainfall and temperature had larger effects upon step-counts in than day length, wind or hours of sunshine. ${ }^{17}$

These research uncertainties matter because of their policy implications. Although season and day length 
are nonmodifiable factors, many countries use daylight saving measures ('changing the clocks') to shift the extra hours of summertime daylight from the very early morning (when most people are asleep) to the evening (when most people are awake). The UK currently changes the clocks forward by 1 hour during summertime ('Single Summer Time'), but the past decade has seen several proposals to extend this by changing the clocks forward by 1 extra hour year round ('Single/Double Summer Time'). The most recent of these proposals was a Daylight Saving Bill which in 2011 was under debate in the House of Commons.

The proposed change to Single/Double Summer Time would give British children an estimated average of 200 extra waking daylight hours per year. ${ }^{26}$ The Bill's accompanying research paper listed "increase[d] opportunities for outdoor activity"27, p.12 as one potential benefit, alongside other public health benefits, such as reduced child and adult injuries from road traffic crashes and reduced greenhouse gas emissions. ${ }^{27,28}$ This predicted increase in children's physical activity would be considerably strengthened if evening daylight were an important, independent contributor to seasonal differences. By contrast, if (nonmodifiable) aspects of the weather were more important, then it might be more effective to target the downstream behavioral mediators - a process facilitated by knowing precisely which aspects of behavior are most affected by season.

The aims of this paper are therefore to test the hypotheses 1) that longer day length predicts increased child physical activity in the late afternoon and early evening, independent of weather conditions; and 2) that any day length effects upon physical activity are partially mediated by effects on children's participation in play, sport, and active travel.

\section{Methods}

\section{Participants}

This paper brings together 2 observational studies, both of which used the same methodology to study physical activity and behavior among 8- to 11-year-olds in Hertfordshire, South-East England. ${ }^{29,30}$ Nine primary schools were selected on the basis of their willingness to cooperate (out of 27 approached), and children and parents provided written informed assent/consent. The first study collected valid data from 115 children in Year 6 (age 10-11, 50\% participation rate), conducting fieldwork between February 2002 and July 2003. The second study collected valid data from 210 children from Years 4, 5, and 6 (age 8 to 11, 55\% participation rate), between July 2005 and March 2006. Our total sample therefore consists of 325 children (170 girls), with a mean age of 9.8 years and a $25 \%$ prevalence of overweight/obesity ${ }^{31}$ (see Table 1).

These studies were approved by the University College London ethics committee for non-NHS human research.

\section{Physical Activity}

We measured physical activity using RT3 triaxial accelerometers (Stayhealthy Inc, USA). These measure body acceleration in 3 planes, giving an overall activity count which provides a valid measure of physical activity in children. ${ }^{32}$ Accelerometers were worn around the waist on the hip from Wednesday to Monday, giving 4 full days of data (Thursday to Sunday). Movement was recorded each minute and periods and, in line with common practice in epidemiological studies, ${ }^{33,34}$ we considered 10 continuous minutes of zero counts as 'nonworn time.' We measured physical activity as the percentage time spent in moderate-to-vigorous physical activity (MVPA) with a cut-point of 970 counts per minute. ${ }^{32}$ As a sensitivity analysis we repeated our analyses using mean overall volume of physical activity (mean counts per minute).

\section{Participation in Out-of-Home Play, Structured Sports, and Active Travel}

Children completed travel and activity diaries for 4 days, adapted from National Travel Survey diaries ${ }^{35}$ and simplified during piloting to ensure children could easily understand them (example extract in the supplementary material). After the monitoring phase a researcher went through the diary with the child to clarify parts which were unclear or incomplete. ${ }^{29}$ This included crosschecking the timings in the diaries against the timings from the accelerometer traces, resolving any apparent discrepancies in discussion with the child. Diary timings were also cross-checked against the Global Positioning Systems (GPS) monitors worn by a subsample of our participants $(\mathrm{N}=111)$ for behaviors involving spatial changes (eg, leaving a building, starting a journey).

The events in the diary were recorded as free text by the children, 16,428 out of $16,664(98.5 \%)$ of which could subsequently be coded according to a hierarchical typology previously described. ${ }^{29}$ In this paper we focus upon 3 behaviors which we have shown were particularly physically active: ${ }^{36}$ out-of-home unstructured play (eg, informal football games, 'playing'); structured sport (eg, sports lessons or training); and active travel (eg, walking, cycling). Within these, we also singled out 'cycling' and 'swimming' events because accelerometers underestimate physical activity from cycling and cannot be worn in water. ${ }^{37}$ As such, if short days/bad weather were associated with increased swimming or cycling, this could create the spurious impression of a decrease in overall physical activity.

For each behavior we calculated its duration (minutes in behavior/total minutes), activity intensity (MVPA minutes in behavior/total minutes in behavior), and activity contribution (duration $\times$ intensity, or MVPA minutes in behavior/total minutes).

\section{Day Length and Weather}

We calculated day length in hours using sunrise and sunset times for London, ${ }^{38}$ which borders Hertfordshire. 
Table 1 Demographic Characteristics of Study Participants and Distribution of Weather Conditions Across Study Days

\begin{tabular}{|c|c|c|c|c|c|c|c|}
\hline & & \multicolumn{2}{|c|}{ Children } & \multicolumn{4}{|c|}{ Days with valid data } \\
\hline & & $\mathbf{N}$ & $\begin{array}{c}\% \text { of } \\
\text { children }\end{array}$ & $\mathbf{N}$ & $\begin{array}{l}\% \text { of } \\
\text { days }\end{array}$ & $\begin{array}{c}\% \text { day } \\
\text { in MVPA }\end{array}$ & $P^{a}$ \\
\hline Full sample & & 325 & 100 & 817 & 100 & 18.0 & - \\
\hline \multirow[t]{2}{*}{ Study } & Study 1 (2002-3) & 115 & 35 & 402 & 49 & 18.0 & 0.98 \\
\hline & Study 2 (2005-6) & 210 & 65 & 415 & 51 & 18.0 & \\
\hline \multirow[t]{2}{*}{ Gender } & Male & 155 & 48 & 372 & 46 & 20.0 & $<0.001$ \\
\hline & Female & 170 & 52 & 445 & 54 & 16.3 & \\
\hline \multirow[t]{3}{*}{ School year } & Year 4 (age 8-9) & 67 & 21 & 132 & 16 & 19.1 & 0.61 \\
\hline & Year 5 (age 9-10) & 91 & 28 & 191 & 23 & 17.9 & \\
\hline & Year 6 (age 10-11) & 167 & 51 & 494 & 60 & 17.8 & \\
\hline \multirow[t]{3}{*}{ Weight status ${ }^{b}$} & Normal/underweight & 244 & 75 & 601 & 74 & 18.0 & 0.84 \\
\hline & Overweight & 59 & 18 & 164 & 20 & 17.7 & \\
\hline & Obese & 22 & 7 & 52 & 6 & 19.4 & \\
\hline \multirow[t]{2}{*}{ Day type } & Weekday & - & - & 491 & 60 & 19.0 & $<0.001$ \\
\hline & Weekend & - & - & 326 & 40 & 16.6 & \\
\hline \multirow[t]{3}{*}{ Day length } & Short (7.9-9.5 hours) & - & - & 261 & 32 & 17.0 & 0.003 \\
\hline & Medium (10.2-12.6 hours) & - & - & 247 & 30 & 16.7 & \\
\hline & Long ( $\geq 14$ hours) & - & - & 309 & 38 & 19.9 & \\
\hline \multirow[t]{3}{*}{ Temperature } & $-2-5^{\circ} \mathrm{C}$ & - & - & 347 & 42 & 18.2 & 0.01 \\
\hline & $5-15^{\circ} \mathrm{C}$ & - & - & 324 & 40 & 16.7 & \\
\hline & $15-25^{\circ} \mathrm{C}$ & - & - & 146 & 18 & 20.6 & \\
\hline \multirow[t]{3}{*}{ Rainfall } & None & - & - & 404 & 49 & 19.5 & $<0.001$ \\
\hline & $0.1-2 \mathrm{~mm}$ & - & - & 268 & 33 & 17.7 & \\
\hline & $\geq 2 \mathrm{~mm}$ & - & - & 145 & 18 & 14.4 & \\
\hline \multirow[t]{3}{*}{ Cloud cover } & $0-1$ oktas & - & - & 236 & 29 & 18.9 & $<0.001$ \\
\hline & $2-6$ oktas & - & - & 224 & 27 & 19.3 & \\
\hline & 7 or 8 oktas & - & - & 357 & 44 & 16.6 & \\
\hline \multirow[t]{3}{*}{ Wind speed } & 0-2 mph & - & - & 305 & 37 & 19.3 & 0.04 \\
\hline & $2-5 \mathrm{mph}$ & - & - & 307 & 38 & 17.1 & \\
\hline & 5-12 mph & - & - & 205 & 25 & 17.4 & \\
\hline
\end{tabular}

Abbreviations: MVPA, moderate-to-vigorous physical activity.

a Univariable tests for heterogeneity in linear regression models, adjusted for clustering by child.

${ }^{\mathrm{b}}$ Calculated using international cut-offs. ${ }^{31}$

As fieldwork was constrained by school term times, day lengths formed 3 clusters: 'short' days (7.9-9.5 hours, November to early February), 'medium' days (10.2-12.6 hours: October, late February, and March), and 'long' days (14.1-16.6 hours, mid-April to July). The Royston weather station in north Hertfordshire ${ }^{39}$ provided dayby-day data for 4 weather variables: mean temperature in degrees centigrade; total rainfall in millimeters; cloud cover at 9:00 AM in oktas (one okta indicates clouds covering one-eighth of the sky); and mean wind speed in miles per hour.

\section{Analysis}

We used linear regression to examine day length and weather effects upon a) proportion time in MVPA and 
b) duration and intensity of participation in play/sport/ active travel. We also fitted the model shown in Figure 1 to examine how far effects on MVPA were mediated by the activity contribution from play, sport or active travel. To test our hypothesis that day length effects would be strongest in the afternoon/evening, we fitted these models separately for the 'pre-3 PM' vs. 'post-3 PM' periods of the day (cut-off chosen as the end of the school day). We also ran these models separately for each hour of the day to pin-point further the timing of any effects.

Although the correlations between day length, temperature, rainfall cloud, and wind were generally low (Pearson's rho $\leq 0.3$ ), day length and temperature were highly collinear $(r h o=0.75)$. We therefore entered only day length into multivariable models, selecting day length because it was always at least a strong a predictor as temperature. We entered day length as a categorical variable (and report p-values for heterogeneity) because visual inspection sometimes indicated nonlinear associations.

All analyses were restricted to days with at least 8 hours of valid, overlapping diary and accelerometer data between 6:00 AM and 11:00 PM ( $=491$ weekdays, $\mathrm{N}=326$ weekend days). We used days not children as our units of analysis because weather varies from day to day. All regression models adjusted for gender, school year, and weight status (as categorical variables), and used robust standard errors to account for clustering of days within children. Substantive findings regarding total effects were unchanged when we used 3-level random intercepts to additionally allow for clustering of children within schools: we do not present these 3-level models because they could not readily be used to estimate direct vs. indirect effects in our mediation analysis. All analyses were conducted in Stata11.1 except the mediation analyses which used MPlus5.

\section{Results}

Across the 817 days with valid data, children spent 18\% of their time in MVPA. This was higher on weekdays (19\% vs. $17 \%$ on weekend days) and in boys (20\% vs. $16 \%$ in girls): study, age, and weight status were not associated with MVPA (see Table 1). These and all other associations presented below were similar or identical for boys and girls (all $P>.01$ for interaction with gender), or when repeated using overall volume of physical activity

\section{Effect of Day Length and Weather on Physical Activity}

Physical activity was associated with day length on both week and weekend days, an association driven by higher levels of physical activity on long days post-3 PM than on short or medium days post-3 PM $(P<.002$ for heterogeneity, see Table 2). This association was little changed after adjusting for cloud cover, rainfall, and wind speed, suggesting the day length effect could not be explained by these aspects of the weather. As hypothesized, the effect was particularly large in the late afternoon and early evening: between 5 PM and 8 PM children spent $22 \%$ time in MVPA on long days vs. $13 \%$ on short/medium days ( $24 \%$ vs. $15 \%$ on weekdays, $20 \%$ vs. $11 \%$ on weekends: see Figure 2). By contrast, long day length had smaller effects upon physical activity in the early afternoon, and there was no evidence of an effect on weekday or weekend mornings (see Figure 2). There was also very little difference between short and medium days in physical activity at any time.

As for the weather variables, temperature showed a very similar pattern to day length (see Table 1) -an unsurprising finding given their collinearity. A different

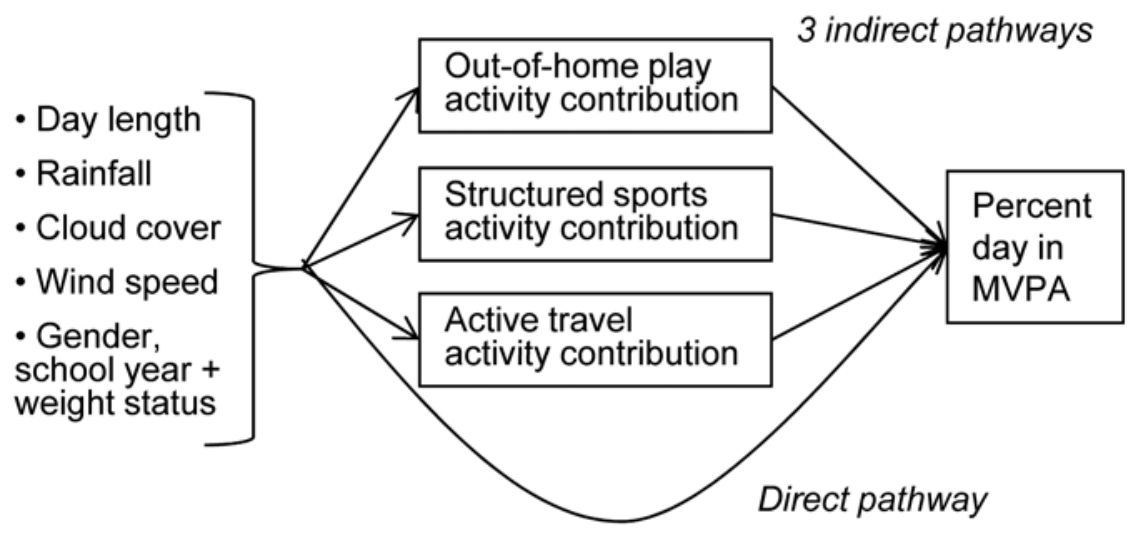

Figure 1 - Mediation model to examine how far participation in 3 physically active behaviors can explain day length or weather effects upon overall physical activity. Activity contribution $=$ duration (proportion of day spent in behavior) $\times$ intensity (proportion of time in behavior spent in MVPA). Temperature not entered due to high collinearity with day length. 


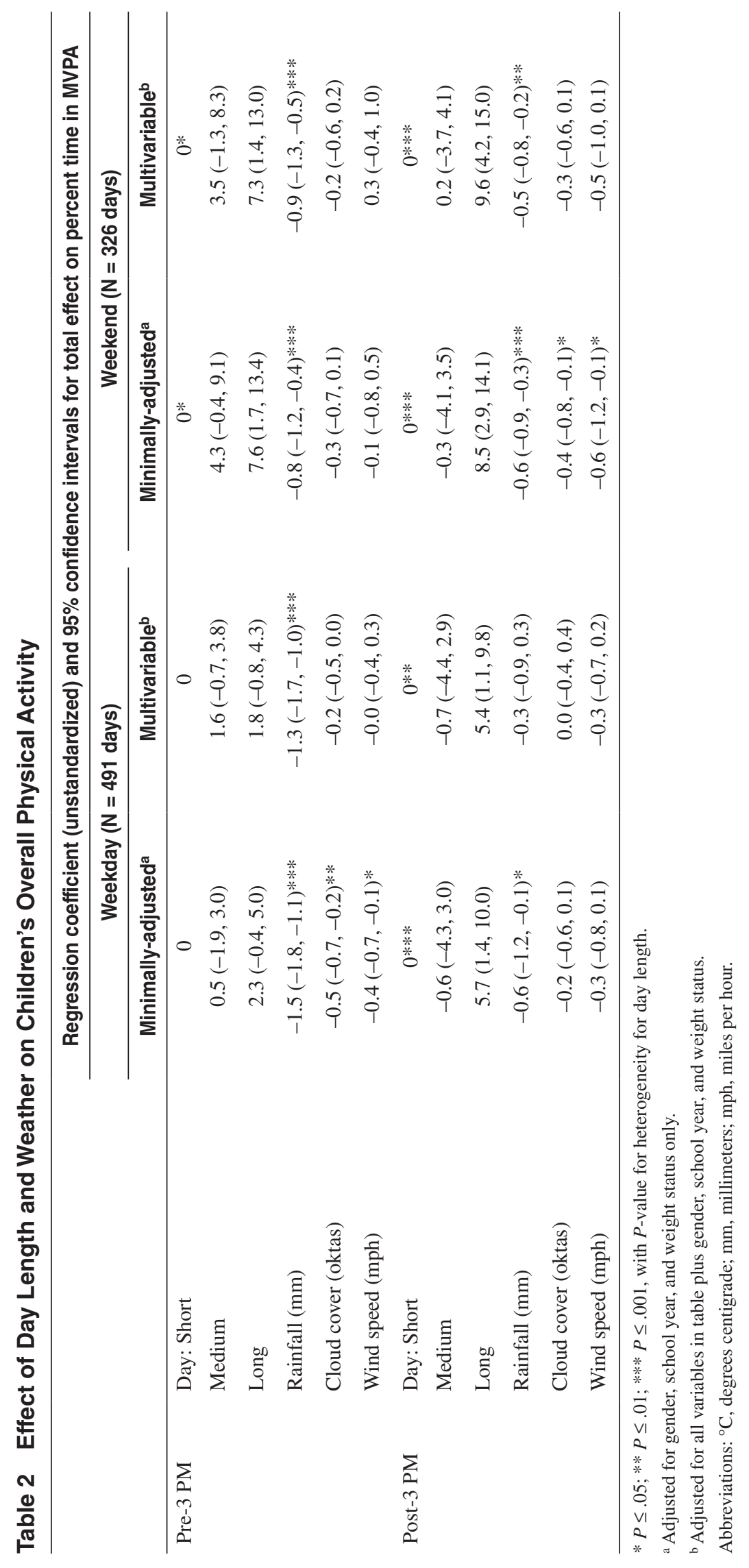




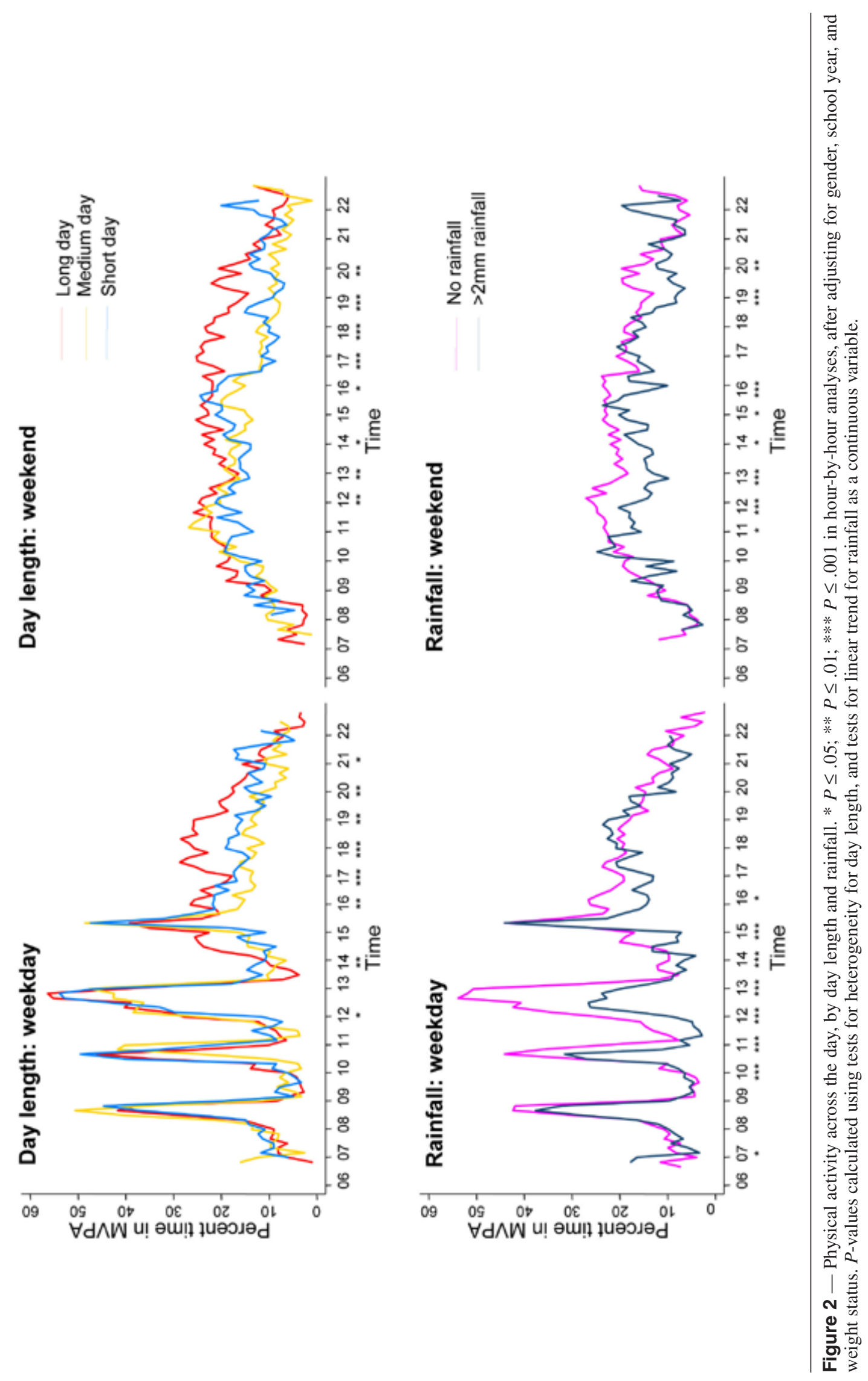


pattern was seen for rainfall, which was associated with lower physical activity during the middle part of the day. On weekdays this effect was particularly pronounced during morning break and lunch break (Figure 2, second and third peaks), although interestingly activity levels were little changed on the journey to and from school (first and fourth peaks). There was no evidence that cloud cover or wind independently predicted physical activity.

\section{Mediating Role of Out-of-Home Play, Structured Sport, and Active Travel}

As shown in Table 3, out-of-home play seemed to mediate part of the effect of long day length upon physical activity post-3 PM. This was true on weekdays and weekends alike, and the magnitude of the indirect (ie, mediated) path was $40 \%$ to $50 \%$ of the total effect. This mediation primarily reflected the substantially greater duration of play during the afternoons and evenings of long days (Figure 3). For example, in the period 4 PM to $8 \mathrm{PM}$, out-of-home play accounted for $3 \%, 7 \%$, and $13 \%$ of children's time on short, medium, and long weekdays; and $7 \%, 5 \%$, and $14 \%$ on weekend days (both $P<.001$ for heterogeneity). There was also evidence that the intensity of children's play was greater post-3 PM (but not pre-3 PM) on long week and weekend days (45\% time in MVPA on long days vs. $32 \%$ on medium days and $20 \%$ on short days, $P<.001$ for heterogeneity; see also Appendix). Exploratory post hoc analyses suggested that this greater intensity reflected a higher proportion of unstructured ball games, one of the most active forms of play: these accounted for 24\% (27/111) of all play events initiated post-3 PM on long days, vs. 2\% (2/83) on short or medium days.

By contrast, there was a trend for longer day length to be associated with a shorter duration of structured sport (Figure 3), leading to an indirect path in the opposite direction on weekdays post-3 PM and also on weekends pre-3 PM (Table 3). In no time period was there strong evidence that active travel formed an indirect path between day length and physical activity (Table 3), despite a trend toward a slightly longer duration of active travel on long days (Figure 3). There was likewise little or no evidence that rainfall, cloud or wind predicted the duration or intensity of participation in any physically active behavior (see Appendix), and no evidence that these weather variables were mediated by play, sport or active travel (Table 3 ).

Finally, duration of swimming and cycling were generally not associated with day length or weather and the trend was for higher duration on longer days with better weather $(\mathrm{eg}, 0.5 \%, 0.6 \%$, and $0.7 \%$ time swimming on short, medium, and long days; $0.3 \%, 0.4 \%$, and $0.8 \%$ time cycling). There was thus no suggestion of information bias such that physical activity was missed or underestimated more often on short or rainy days.

\section{Discussion}

This study of 325 8-11 year-olds found higher overall physical activity on long week and weekend days, but no difference between short and medium days. The effect of long day length was largest between 5 PM and 8 PM, and persisted after adjusting for rainfall, cloud cover, and wind. Up to half the effect was mediated by a substantially greater duration and intensity of out-of-home play on long days. Participation in structured sports and active travel showed less variation by day length, but in some time periods the effect of long day length was partly offset by a reduced activity contribution from sports. Rainfall independently predicted lower physical activity in the morning and early afternoon, an effect not explained by participation in play, sport or active travel. There was no evidence for independent effects of cloud cover or wind, and temperature was too collinear with day length to examine separately.

The specificity of the day length effect in the late afternoon/early evening is consistent with previous studies showing larger seasonal differences after school hours ${ }^{14,16}$ and extends previous research by showing that this also applies at weekends. This specificity supports the hypothesis that daylight itself has a causal effect on child physical activity in northern climates, a hypothesis further strengthened by our novel demonstration that the day length effect was little changed after adjusting for rainfall, cloud cover, and wind. This therefore supports claims that (alongside other benefits) postponing sunset through daylight saving measures would promote child physical activity. ${ }^{28}$ This is particularly the case given that the after-school period has been described as the 'critical hours' for children's physical activity, ${ }^{40,41}$ and given that the absence of any day length effects in the morning suggests that afternoon activity gains would not be counterbalanced by earlier decreases. On the other hand, we did not observe a dose response effect: while physical activity was higher on long days (sunset post-8 PM), there was no difference between medium days (sunset around 6 PM) and short days (sunset pre-5 $\mathrm{PM}$ ). If replicated in other datasets, this may indicate that the benefits of daylight saving measures would be concentrated in the spring/autumn transitions between medium and long days.

The key mediating role of out-of-home play confirms the importance of play for child physical activity $5,6,36,41$ and is consistent with parents' identification of darkness as a barrier to permitting unsupervised play outdoors. ${ }^{4}$ It replicates recent evidence that the duration and/or intensity of children's outdoor activity increases in spring/ summer, ${ }^{24,41}$ and extends this by highlighting play (perhaps particularly informal ball games) as the activities most affected. This central role of play arguably undermines somewhat recommendations to counter seasonal variation by building infrastructure for indoor sports. ${ }^{25,43}$ 


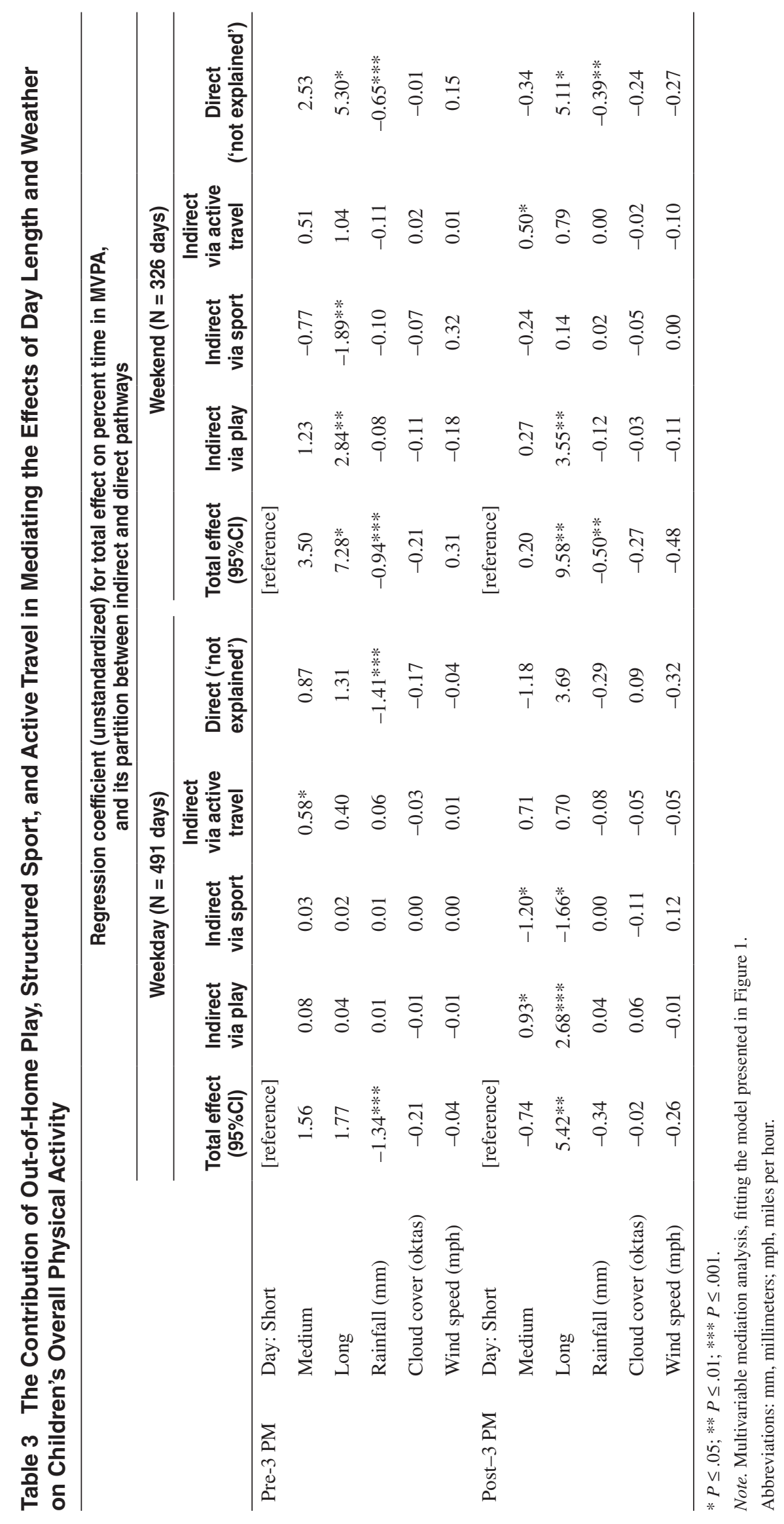




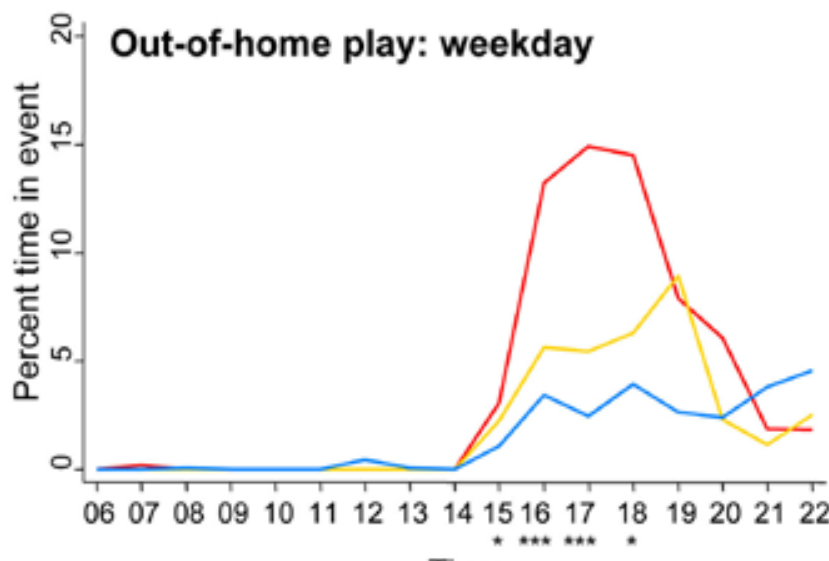

Time
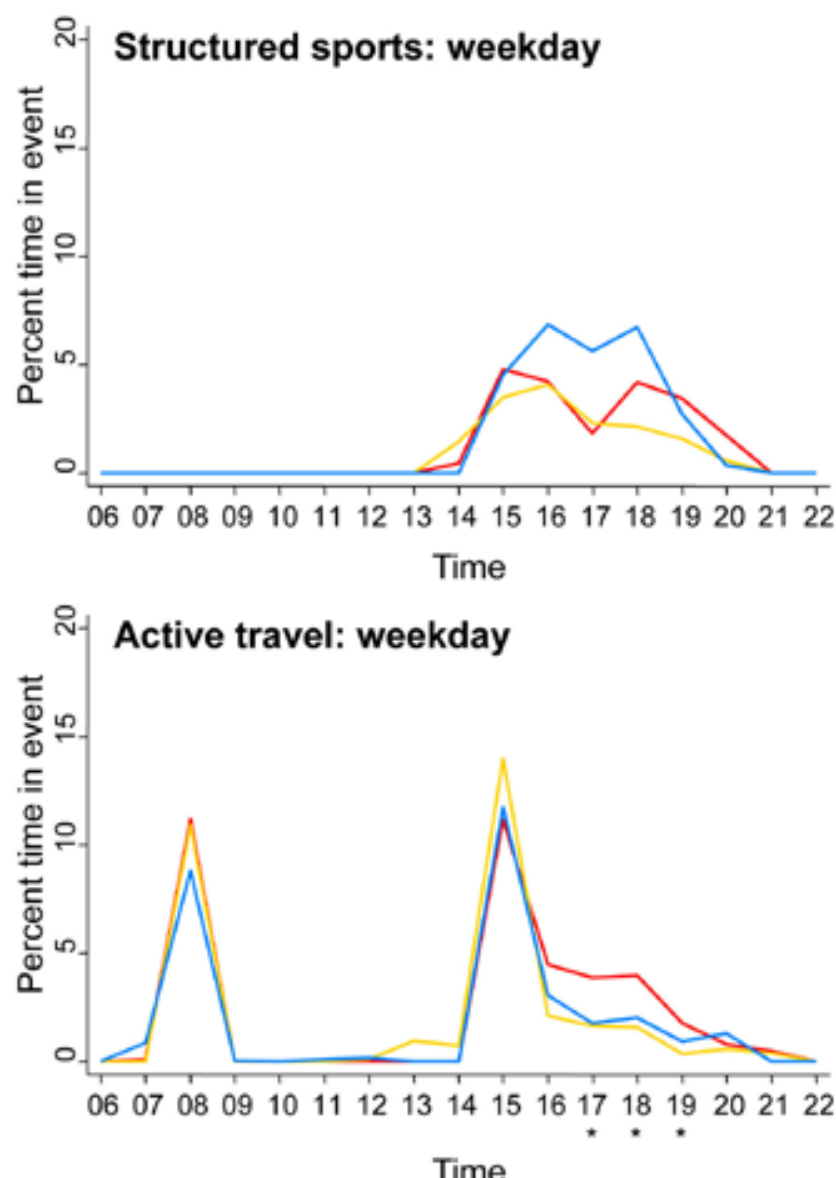

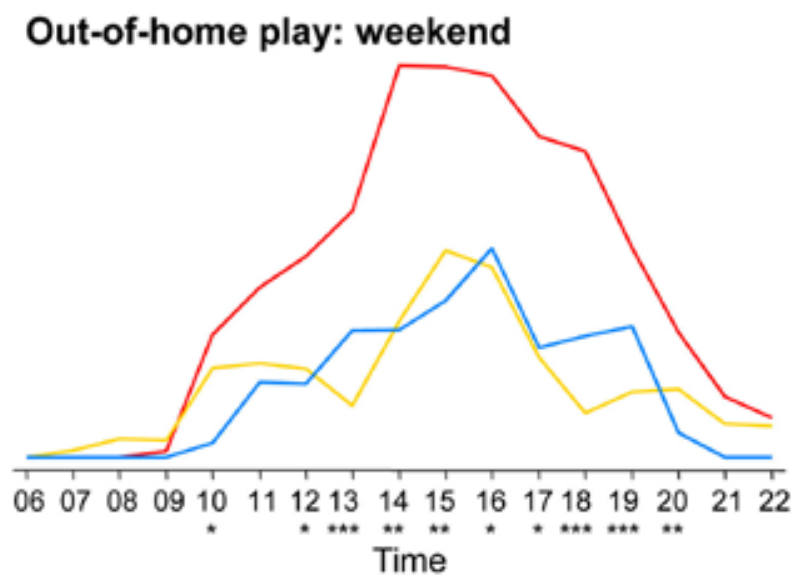

Structured sports: weekend

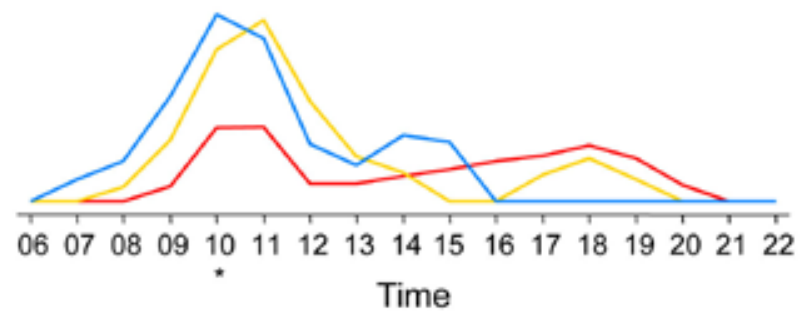

Active travel: weekend

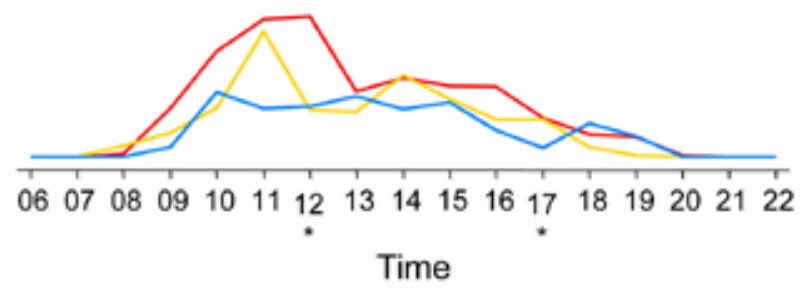

Figure 3 - Percentage of time spent participating in physically active behaviors, by day length. * $P \leq .05 ; * * P \leq .01 ; * * * P \leq .001$ in hour-by-hour analyses, after adjusting for gender, school year, and weight status. $P$-values calculated using tests for heterogeneity.

Insofar as such policies seem unlikely to facilitate informal play (much of which occurs very near the home ${ }^{44}$ ), they may reduce seasonal differences less than daylight saving measures. Nevertheless, some benefit is plausible given the potential hinted at in our data for increased structured sports on short and medium days to offset in part the effect of reduced play. This offsetting effect may stem from the fact that organized activities such as football leagues run primarily in the autumn/winter months, and supports the importance of such activities in months where out-of-home play is less attractive or not permitted by parents. Moreover, the smaller role of sports and active travel in explaining seasonal differences does not lessen their importance as targets for 
physical activity interventions in general. ${ }^{36}$ Indeed, this importance is in some ways enhanced by their relative imperviousness to day length and weather, a 'weatherresistance' particularly notable for active commuting to school. This contrasted with markedly lower physical activity during school hours on rainy days, suggesting that schools may need to do more to provide alternative options for indoor activity.

Besides these substantive issues, our findings also have methodological implications. The importance of day length confirms the difficulty of comparing data collected at different times of year, ${ }^{8,9,18}$ while the independent influence of rainfall indicates that analogous weather effects may operate over even shorter timescales. This complicates between-study comparisons, could create within-study bias, and at a minimum may introduce 'noise' which decreases power and precision. We therefore recommend that future studies of child physical activity consider adjusting for day length and rainfall.

We hope future studies will also address the limitations of this research, 3 of which may have lead to underestimation of the effects we support. First our use of accelerometer data recorded on a minute-by-minute basis is longer than the ideal epoch length of $\leq 15$ seconds $^{37}$ and may have lead us to miss brief sporadic MVPA. Second, we may have underestimated the importance of our behavioral mediators because of inaccuracies in children's reporting of the timing of events and because children did not always record garden play separately. One potential resolution would be to enhance diary data by using global positioning systems (GPS) monitors to identify when children were outside. ${ }^{24}$ Third, only dayby-day weather data were available to us and, in the case of cloud cover, this was only available at one point in time; this may have diluted the magnitude of the weather effects which would be seen using hour-by-hour data.

A further limitation is that high collinearity and relatively small sample size prevented us from distinguishing day length and temperature effects. Day length had stronger minimally-adjusted effects which, in combination with the specificity of the effect to the afternoon/ evening, lead us to believe that day length played a greater causal role. It would, however, be valuable to examine this directly in more informative datasets, particularly as one New Zealand study found temperature was more important than day length. ${ }^{17}$ Finally, further research is also needed before it can be assumed that these findings generalize to settings with more extreme weather (eg, extreme heat ${ }^{45}$ ), or to preschool children (who may not show seasonal differences in physical activity ${ }^{18}$ ).

To conclude, these findings suggest that primary school children in South-East England are more physically active on long days, partly because they spend more time playing outside the home. This represents the most direct evidence yet that (at least at some points of the year) redistributing daylight hours to the afternoon might prove an effective population-level intervention to promote child physical activity. In combination with the evidence that such measures would avert road traffic crashes and reduce greenhouse gas emissions, ${ }^{27}$ this study therefore bolsters the public health arguments in favor of daylight saving measures such as those recently under consideration in the UK.

\section{Acknowledgments}

Many thanks to the children who took part in these studies, and to their parents and teachers. We are grateful to the Environment Department of Hertfordshire County Council, a non-academic partner which facilitated much of the fieldwork. We also greatly appreciate the work of Belinda Brown, Yi Gong, Kay Kitazawa, Lindsey Lucas, and Jill Turbin, who assisted in carrying out the fieldwork, and Laurel Edmunds, Ruth Sullivan, and Kate Westgate for providing advice on the use and analysis of accelerometers. Funding for the first study ('Reducing children's car use: the health and potential car dependency impacts") was provided by UK Engineering and Physical Sciences Research Council, grant GR/N33638. Funding for the second study ('Children's Activities Perceptions and Behavior in the Local Environment (CAPABLE)') was provided by UK Engineering and Physical Sciences Research Council, grant GR/T09378/01. AG completed this report during a Post-Doctoral Research Fellowship supported by the National Institute for Health Research. The views expressed in this publication are those of the authors and not necessarily those of the NHS, the National Institute for Health Research or the Department of Health.

\section{References}

1. Department of Health. At least 5 a week: physical activity and health outcomes: a review of the Chief Medical Officer. London: Department of Health; 2004.

2. Mutrie N, Parfitt G. Physical activity and its link with mental, social and moral health in young people. In: Biddle $\mathrm{S}$, Sallis J, Cavill N, eds. Young and active? Young people and health-enhancing physical activity-evidence and implications. London: Health Education Authority; 1998.

3. Butland B, Jebb SA, Kopelman P, et al. Foresight. Tackling obesities: future choices-project report. London: Government Office for Science; 2007.

4. Strong WB, Malina RM, Blimkie CJ, et al. Evidence based physical activity for school-age youth. J Pediatr. 2005;146(6):732-737. PubMed doi:10.1016/j. jpeds.2005.01.055

5. Sallis JF, Prochaska JJ, Taylor WC. A review of correlates of physical activity of children and adolescents. Med Sci Sports Exerc. 2000;32(5):963-975. PubMed doi:10.1097/00005768-200005000-00014

6. Ferreira I, van der Horst K, Wendel-Vos W, Kremers S, van Lenthe FJ, Brug J. Environmental correlates of physical activity in youth-a review and update. Obes Rev Mar. 2007;8(2):129-154.

7. Davison KK, Lawson CT. Do attributes in the physical environment influence children's physical activity? A review of the literature. Int J Behav Nutr Phys Act. 2006;3:19. PubMed doi:10.1186/1479-5868-3-19

8. Goran MI, Nagy TR, Gower BA, et al. Influence of sex, seasonality, ethnicity, and geographic location on the components of total energy expenditure in young children: implications for energy requirements. Am J Clin Nutr. 1998;68(3):675-682. PubMed 
9. Beighle A, Alderman B, Morgan MF, Le Masurier G. Seasonality in children's pedometer-measured physical activity. Research Quarterly in Exercise Science. 2008;79(2):256-260. PubMed doi:10.5641/1932503 08X13086753543734

10. Tremblay MS, Barnes JD, Esliger DW, Copeland JL. Seasonal variation in physical activity of Canadian children assessed by accelerometry (abstract). Pediatr Exerc Sci. 2005; 17:73.

11. Griew P, Page A, Thomas S, Hillsdon M, Cooper AR. The school effect on children's school time physical activity: the PEACH Project. Prev Med. 2010;51(3-4):282-286. PubMed doi:10.1016/j.ypmed.2010.06.009

12. Riddoch CJ, Mattocks C, Deere K, et al. Objective measurement of levels and patterns of physical activity. Arch Dis Child. 2007;92(11):963-969. PubMed doi:10.1136/ adc. 2006.112136

13. Kristensen PL, Korsholm L, Moller NC, Wedderkopp $\mathrm{N}$, Andersen LB, Froberg K. Sources of variation in habitual physical activity of children and adolescents: the European youth heart study. Scand J Med Sci Sports. 2008;18(3):298-308. PubMed doi:10.1111/j.16000838.2007.00668.x

14. Kolle E, Steene-Johannessen J, Andersen LB, Anderssen SA. Seasonal variation in objectively assessed physical activity among children and adolescents in Norway: a cross-sectional study. Int J Behav Nutr Phys Act. 2009;6:36. PubMed doi:10.1186/1479-5868-6-36

15. Wennlöf AH, Yngve A, Nilsson TK, Sjostrom M. Serum lipids, glucose and insulin levels in healthy schoolchildren aged 9 and 15 years from central Sweden: reference values in relation to biological, social and lifestyle factors. Scand J Clin Lab Invest. 2005;65(1):65-76. PubMed doi:10.1080/00365510410003110

16. Loucaides CA, Chedzoy SM, Bennett N. Pedometerassessed physical (ambulatory) activity in Cypriot children. Eur Phys Educ Rev. 2003;9(1):43-55. doi:10.1177/1356336X03009001179

17. Duncan JS, Hopkins WG, Schofield G, Duncan EK. Effects of weather on pedometer-determined physical activity in children. Med Sci Sports Exerc. 2008;40(8):1432-1438. PubMed doi:10.1249/MSS.0b013e31816e2b28

18. Carson V, Spence JC. Seasonal variation in physical activity among children and adolescents: a review. Pediatr Exerc Sci. 2010;22(1):81-92. PubMed

19. Mattocks C, Leary S, Ness A, et al. Intraindividual variation of objectively measured physical activity in children. Med Sci Sports Exerc. 2007;39(4):622-629. PubMed doi:10.1249/mss.0b013e318030631b

20. Rowlands AV, Hughes DR. Variability of physical activity patterns by type of day and season in 8-10-year-old boys. Res Q Exerc Sport. 2006;77(3):391-395. PubMed doi:10 $.5641 / 027013606 X 13080770014969$

21. Fisher A, Reilly JJ, Montgomery C, et al. Seasonality in physical activity and sedentary behavior in young children. Pediatr Exerc Sci. 2005;17:31-40.

22. Hagger M, Cale L, Almond L, Kruger A. Children's physical activity levels and attitudes towards physical activity. Eur Phys Educ Rev. 1997;3:144-164. doi:10.1177/1356336X9700300205

23. Ridgers ND, Stratton G, Fairclough SJ. Physical activity levels of children during school playtime. Sports Med. 2006;36(4):359-371. PubMed doi:10.2165/00007256200636040-00005
24. Cooper AR, Page AS, Wheeler BW, Hillsdon M, Griew P, Jago R. Patterns of GPS measured time outdoors after school and objective physical activity in English children: the PEACH project. Int J Behav Nutr Phys Act. 2010;7:31. PubMed doi:10.1186/1479-5868-7-31

25. Tucker P, Gilliland J. The effect of season and weather on physical activity: a systematic review. Public Health. 2007;121(12):909-922. PubMed doi:10.1016/j. puhe.2007.04.009

26. Hillman M. Making the most of daylight hours: the implications for Scotland. London: Policy Studies Institute; 2010.

27. Bennett O. Daylight Saving Bill 2010-11. Research paper 10/78. London: House of Commons Library; 2010.

28. Hillman M. More daylight, better health: why we shouldn't be putting the clocks back this weekend. BMJ. 2010;341:c5964. PubMed doi:10.1136/bmj.c5964

29. Mackett RL, Lucas L, Paskins J, Turbin J. The therapeutic value of children's everyday travel. Transp Res Part A Policy Pract. 2005;39(2-3):205-219. doi:10.1016/j. tra.2004.09.003

30. Mackett R, Brown B, Gong Y, Kitazawa K, Paskins J. Children's independent movement in the local environment. Built Environ. 2007;33(4):454-468. doi:10.2148/ benv.33.4.454

31. Cole TJ, Bellizzi MC, Flegal KM, Dietz WH. Establishing a standard definition for child overweight and obesity worldwide: international survey. BMJ. 2000;320(7244):12401243. PubMed doi:10.1136/bmj.320.7244.1240

32. Rowlands AV, Thomas PW, Eston RG, Topping R. Validation of the RT3 triaxial accelerometer for the assessment of physical activity. Med Sci Sports Exerc. 2004;36(3):518524. PubMed doi:10.1249/01.MSS.0000117158.14542.E7

33. Page AS, Cooper AR, Griew P, Davis L, Hillsdon M. Independent mobility in relation to weekday and weekend physical activity in children aged 10-11 years: The PEACH Project. Int J Behav Nutr Phys Act. 2009;6:2. PubMed doi:10.1186/1479-5868-6-2

34. van Sluijs EM, Jones NR, Jones AP, Sharp SJ, Harrison F, Griffin SJ. School-level correlates of physical activity intensity in 10-year-old children. Int J Pediatr Obes. 2010; (Sep):20. PubMed

35. Kershaw A. National Travel Survey. Technical Report 2000. London: Office for National Statistics; 2001. doi:10.1016/j.ypmed.2011.07.019

36. Goodman A, Paskins J, Mackett R. Activity compensation and activity synergy in British 8-13 year olds. Prev Med. 2011;53(4-5):293-8. PubMed

37. Corder K, Brage S, Ekelund U. Accelerometers and pedometers: methodology and clinical application. Curr Opin Clin Nutr Metab Care. 2007;10(5):597-603. PubMed doi:10.1097/MCO.0b013e328285d883

38. Timeanddate.com. Sunrise and Sunset for U.K.-England-London. Accessed from http://www.timeanddate. com/worldclock/astronomy.html?n=136 on 14 December 2009.

39. Royston (Iceni) Weather Station. Daily Weather Observations (Historical) Accessed from http://www.iceni.org.uk/ index/dwolinks.htm on 14 December 2009.

40. Atkin AJ, Gorely T, Biddle SJ, Marshall SJ, Cameron N. Critical hours: physical activity and sedentary behavior of adolescents after school. Pediatr Exerc Sci. 2008;20(4):446-456. PubMed 
41. Cleland V, Crawford D, Baur LA, Hume C, Timperio A, Salmon J. A prospective examination of children's time spent outdoors, objectively measured physical activity and overweight. Int J Obes (Lond). 2008;32(11):1685-1693. PubMed doi:10.1038/ijo.2008.171

42. Hillman M, Adams J, Whitelegg D. One false move.... A study of children's independent mobility. London: Policy Studies Institute; 2001.

43. Sallis JF, Bauman A, Pratt M. Environmental and policy interventions to promote physical activity. Am J Prev Med. 1998;15(4):379-397. PubMed doi:10.1016/S07493797(98)00076-2
44. Jones AP, Coombes EG, Griffin SJ, van Sluijs EM. Environmental supportiveness for physical activity in English schoolchildren: a study using Global Positioning Systems. Int J Behav Nutr Phys Act. 2009;6:42. PubMed doi:10.1186/1479-5868-6-42

45. Baranowski T, Thompson WO, Durant RH, Baranowski J, Puhl J. Observations on physical-activity in physical locations - age, gender, ethnicity, and month effects. Res Q Exerc Sport. 1993;64(2):127-133. PubMed 